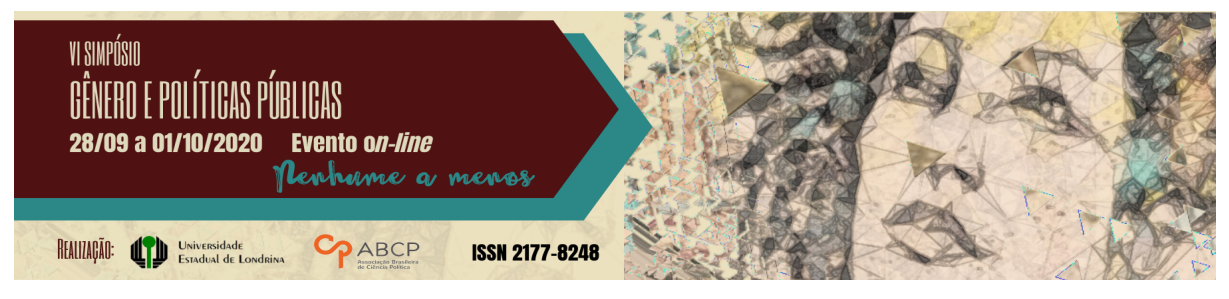

\title{
Educação em gênero sob ataque: análise de legislações educacionais de municípios do Paraná objeto de Arguição de Descumprimento de Preceito Fundamental (ADPF)
}

\author{
Isabela Vince Esgalha Fernandes ${ }^{1}$; Sinara Pollom Zardo²
}

\section{Resumo}

O Brasil assiste a um retrocesso no que se refere às políticas educacionais relacionadas à temática de gênero. Tal fenômeno passou a tomar força a partir da retirada das diretrizes relacionadas à gênero do Plano Nacional de Educação, em 2014. Esta ocorrência teve como consequência a retirada do tema de legislações Brasil à fora. Em verdade, em muitos locais verificou-se expressa censura da inclusão da temática, a despeito da existência de respaldo de diplomas nacionais e internacionais assegurando a necessidade da implementação de medidas educacionais para a superação da violência de gênero e alcance da igualdade. Ademais, as normas aprovadas constituem flagrante afronta a preceitos constitucionais, motivo pelo qual muitas delas tornaram-se alvo do ajuizamento de arguição de descumprimento de preceito fundamental junto ao STF. Um Estado destacou-se pela quantidade de ações: o Paraná conta com quatro ADPF's contra legislações de Foz do Iguaçu, Londrina, Cascavel e Paranaguá. Assim, o objetivo deste artigo é analisar o conteúdo destas legislações, bem como a utilização do instrumento da ADPF no enfrentamento ao retrocesso na implementação de políticas educacionais acerca do tema.

Palavras-chave: educação; gênero; controle de constitucionalidade.

\footnotetext{
${ }^{1}$ Mestranda em Direitos Humanos e Cidadania pela Universidade de Brasília (UNB) Bolsistas Capes - isabelavef@gmail.com

2 Professora do Departamento de Teoria e Fundamentos da Faculdade de Educação. Docente do Programa de Pós-Graduação em Educação e do Programa de PósGraduação em Direitos Humanos e Cidadania da Universidade de Brasília (UnB) sinarazardo@gmail.com
}

GT 19 - Sexualidade, gênero e políticas educacionais 


\title{
Gender education under attack: analysis of educational legislation in Paraná municipalities that is the object of an infringement of a fundamental precept (ADPF)
}

\begin{abstract}
Brazil is experiencing a setback in terms of educational policies related to gender. This phenomenon started to take force after the removal of the guidelines related to gender from the National Education Plan, in 2014. This occurrence had as a consequence the removal of the theme of Brazilian legislation abroad. In fact, in many places, there was a clear censure of the inclusion of the theme, despite the existence of support from national and international diplomas, ensuring the need to implement educational measures to overcome gender violence and achieve equality. In addition, the approved rules constitute a flagrant affront to constitutional precepts, which is why many of them have become the target of filing an allegation of non-compliance with a fundamental precept with the STF. One State stood out for the number of actions: Paraná has four ADPFs against laws in Foz do Iguaçu, Londrina, Cascavel and Paranaguá. Thus, the objective of this article is to analyze the content of these laws, as well as the use of the ADPF instrument to face the setback in the implementation of educational policies on the subject.
\end{abstract}

Keywords: education; gender; constitutionality control.

Testemunhamos, nos últimos anos, gigantes retrocessos no que se refere à agenda de gênero no País, inclusive e especialmente em relação ao âmbito educacional. Tal fenômeno tornou-se mais visível durante o processo de aprovação do Plano Nacional de Educação, promulgado em 2014 pela Lei $\mathrm{n}^{\circ} 13.005$.

A construção do projeto de lei do II Plano Nacional de Educação que tramitou no Congresso Nacional entre 2010 e 2014, remete à Conferência Nacional de Educação (CONAE), ocorrida em 2010. Símbolo da participação democrática, o evento promoveu importantes diálogos entre atores educacionais de todo o país que juntos refletiram acerca das demandas e obstáculos para a organização do sistema nacional de educação. Uma das deliberações da Conferência de 2010 refere-se à inclusão dos temas relacionados à gênero e diversidade de forma transversal nas atividades e conteúdos escolares: 
Eixo IV, "g": Inserir os estudos de gênero, identidade de gênero, orientação sexual, diversidade sexual educação sexual, como disciplina obrigatória, no currículo da formação inicial e continuada, nas atividades de ensino, pesquisa e extensão, nas licenciaturas e bacharelado, na pós-graduação, no ensino fundamental e médio, em todas as áreas do conhecimento, de forma interdisciplinar, transdisciplinar e transversal, articulando-os à promoção dos direitos humanos - meta do Plano Nacional de Educação em Direitos Humanos (BRASIL, 2010, p.144)

Apesar do reconhecimento da relevância do tema, é importante contextualizar o cenário político do período no Brasil, uma vez que teve significativo impacto nos desdobramentos em relação à aprovação do PNE, sobretudo no que se refere à questão de gênero.

Nas eleições de 2010, houve um fortalecimento dos setores religiosos conservadores no Congresso Nacional, com significativa ampliação de representantes políticos filiados a estes setores, que passaram a controlar comissões estratégicas, como a Comissão de Direitos Humanos, criando entraves ao desenvolvimento de projetos relacionados à defesa e à promoção de direitos de mulheres, negros, LGBT, entre outros. Ademais, o período foi caracterizado por um afastamento do governo federal em relação aos movimentos sociais, enfraquecendo as agendas políticas relacionadas a esses grupos (MISKOLCI; CAMPANA, 2017).

O Projeto de lei do PNE, inicialmente encaminhado ao Congresso, continha, entre as diretrizes, a "superação das desigualdades educacionais, com ênfase na promoção da igualdade racial, regional, de gênero e de orientação sexual e na erradicação de todas as formas de discriminação" (REIS; EGGERT, 2017).

Durante a tramitação do projeto, porém, ganhou projeção a discussão acerca da denominada "ideologia de gênero", falácia amplamente utilizada pelos setores conservadores para disseminar 
desinformação acerca das questões de gênero e diversidade (REIS; EGGERT, 2017, p.18).

Em síntese, pregava-se que a ideologia de gênero configuraria uma tentativa de doutrinação com raízes marxistas que defenderia a desconstrução dos papéis de gênero, ameaçando à família, o matrimônio e aos costumes. A propagação de tais informações não tinha, obviamente, qualquer amparo científico, mas um claro objetivo de impedir a promoção de direitos relacionados às mulheres e LGBTs. A estratégia surtiu efeito. As previsões relacionadas ao tema gênero foram retiradas do texto aprovado do PNE.

Esta ocorrência, além do obvio retrocesso que representou à luta pela igualdade de gênero, teve como consequência o fortalecimento destes setores conservadores que, amparados pelo acontecimento, foram bem-sucedidos na retirada do tema quando da aprovação de planos estaduais e municipais de educação Brasil à fora. Entretanto, em muitos locais, verificou-se não apenas um silêncio normativo acerca do tema, mas expressa censura nas legislações destinadas ao norteamento de políticas educacionais.

Ocorre que a inserção e problematização da temática de gênero e violência de gênero nas escolas já está há muito amparada por tratados internacionais ratificados pelo Brasil, como é o caso da Convenção Belém do Pará3, e também pela Lei Maria da Penha, que prevê, entre suas medidas preventivas ${ }^{4}$, a criação e promoção de programas educacionais, bem como seu destaque nos currículos escolares de todos os níveis de ensino acerca da temática (BRASIL, 2006). Além disso, estes diplomas claramente contrariam dispositivos e princípios constitucionais, o que revela sua clara ilegalidade.

Desta forma, diversas destas legislações, que criaram entraves à implementação de políticas de gênero tornaram-se alvo do ajuizamento de arguição de descumprimento de preceito fundamental junto ao 
Supremo Tribunal Federal, considerando sua manifesta afronta ao Estado Democrático. Um Estado destacou-se pela quantidade de ações desta natureza: o Estado do Paraná conta com quatro ADPFs contra legislações das cidades de Foz do Iguaçu, Londrina, Cascavel e Paranaguá5.

Assim, o objetivo deste artigo é analisar o conteúdo (BARDIN, 2006) destas legislações, que representam evidente resistência do poder público na implementação de políticas que buscam a igualdade de gênero, bem como a utilização do instrumento da ADPF no enfrentamento ao retrocesso na implementação de políticas educacionais acerca do tema. Metodologicamente, utilizar-se-á da abordagem qualitativa e da análise documental para realização da pesquisa.

No primeiro tópico, faremos uma breve explanação acerca da Arguição de Preceito Fundamental (ADPF), instrumento de controle de constitucionalidade previsto na Constituição Federal para enfrentar eventuais vícios de inconstitucionalidade em atos normativos tais quais legislações municipais.

Em seguida, analisaremos as ações ajuizadas em cada um dos municípios, os trechos das normas que vetaram a temática de gênero impugnados pelos requerentes com a propositura das ADPFs e o resultado de cada uma das ações. O trabalho encerra-se com uma reflexão acerca do papel da ADPF e do STF na garantia e proteção de direitos.

\section{O exercício do controle de constitucionalidade através da Arguição de Descumprimento Fundamental (ADPF)}

A proteção dos direitos e liberdades fundamentais, na modernidade, em regra está amparada na separação entre os poderes e na supremacia atribuída ao texto constitucional, que reflete o conjunto

5 ADPF's n ${ }^{\circ}$ 526, 600, 460 e 461, respectivamente. 
de regras que sustenta o projeto de sociedade a ser desenvolvido a partir das aspirações da soberania popular, figurando como elemento imprescindível para a garantia e manutenção do Estado Democrático de Direito.

A configuração deste sistema apresenta algumas variações a depender do Estado em que vigora. Na maior parte das vezes, entretanto, advém da combinação do sufrágio universal com a eleição de representantes que atuam, sobretudo, através da elaboração de leis que devem obedecidas por todos como reflexo do poder popular. Neste contexto, a lei possui o papel de regulamentar "os espaços e condições nos quais autoridade estatal e liberdade individual se tocam" (MENDES, 2008, p. 03).

Neste complexo sistema permeado de disputas, coube ao poder judiciário o controle das leis, através da ferramenta do controle de constitucionalidade. Em suma, o objetivo é garantir que as decisões políticas, traduzidas por leis e atos normativos, se mantenham alinhadas ao disposto na Constituição Federal, lei mais importante de nosso ordenamento jurídico, à qual é atribuída uma superioridade hierárquico-normativa em relação às demais leis e/ou atos normativos.

Assim, caso o alinhamento não ocorra, o ato normativo ou lei em análise será inválido (NUNES JÚNIOR, 2019). Esta função, em último grau, é atribuída ao Tribunal Constitucional, representado no Brasil pelo Supremo Tribunal Federal (STF).

Diversos e pertinentes são os questionamentos acerca do exercício desta função, que incluem a reflexão acerca dos limites e adequação de tal instrumento na manutenção da democracia, vez que coloca nas mãos do judiciário a palavra final acerca da interpretação da vontade popular, o que soa no mínimo paradoxal, considerando que a tomada de decisões coletiva constitui um dos pilares do regime democrático que aspiramos (MENDES, 2008).

Para além das discussões, o fato é que o controle de constitucionalidade está disposto na Constituição em vigor, é 
amplamente utilizado no Brasil. A verificação da compatibilidade das leis em relação à constituição não é, contudo, uma tarefa simples. Isto ocorre porque o conteúdo constitucional não se resume apenas ao texto contido na Carta Magna, como nos ensina seu art. 5, § $2^{\circ}$ :

Os direitos e garantias expressos nesta Constituição não excluem outros decorrentes do regime e dos princípios por ela adotados, ou dos tratados internacionais em que a República Federativa do Brasil seja parte (BRASIL, 1988).

Além disso, após a emenda constitucional 45/2004, passaram a possuir força de norma constitucional os tratados e convenções internacionais de direitos humanos aprovados por três quintos dos votos de cada um dos integrantes de cada casa do Congresso Nacional, em dois turnos.

Assim, é preciso verificar a observância do normativo infraconstitucional em relação ao texto constitucional; aos princípios que decorrem da Constituição Federal e aos tratados internacionais de direitos humanos 6 .

Entre as modalidades para o exercício do controle de constitucionalidade está a Arguição de Descumprimento de Preceito Fundamental (ADPF), ação prevista no art. 102, $\S 1^{\circ}$ da Constituição Federal de 1988. Esta ferramenta de controle de constitucionalidade, a qual o julgamento compete exclusivamente ao STF, apenas foi regulamentada em 1999, pela Lei $\mathrm{n}^{\circ} 9.882$.

A função da ADPF é evitar ou reparar lesão ao preceito fundamental, resultante de ato do poder público. ${ }^{7}$ A norma constitucional não conceitua o que seria preceito fundamental, deixando a cargo da doutrina e jurisprudência identificar o que poderia ser incluído em tal classificação.

6 Art. $5, \S 3^{\circ}, \mathrm{CF} / 1988$.

7 Art. $1^{\circ}$, "caput", Lei 9.882/1999 
Apesar de não haver previsão formal que determine o alcance da designação, é razoável inferir que a expressão preceito fundamental indicaria que sua eventual violação repercutiria de forma mais grave no sistema jurídico (BARROSO, 2012). Para Nunes Júnior (2019, p. 590), algumas das previsões constitucionais poderiam facilmente ser identificadas como preceitos, tais como os princípios fundamentais da República Federativa do Brasil (arts. $1^{\circ}$ a $4^{\circ}, \mathrm{CF}$ ); os direitos e garantias fundamentais (arts. $5^{\circ}$ a 17, CF); as cláusulas pétreas (art. 60, § 4 , CF); os princípios constitucionais sensíveis (art. 34, VII, CF).

Ao vislumbrar indício de inconstitucionalidade que caiba o ajuizamento de ADPF, é preciso observar que a Lei $\mathrm{n}^{\circ}$ 9.882/1999 estipulou que o rol de legitimados para a propositura da ADPF seriam os mesmos que os previstos para a ação direta de inconstitucionalidade e a ação declaratória de constitucionalidade, previstos no art. 103 da CF/19888. Nestes termos, nós, como cidadãos, não podemos ajuizar esta modalidade de ação para o controle de constitucionalidade. Ressalta-se, entretanto, que a lei que regulamenta a ADPF possibilita ao interessado que solicite à Procuradoria Geral da República a propositura da ação, que decidirá pela pertinência de seu cabimento.

A ADPF seria um dos instrumentos de controle repressivo de constitucionalidade, o que significa dizer que é cabível após o ingresso da lei ou ato normativo no ordenamento jurídico brasileiro. Entre os objetos da ADPF estão, portanto, legislações municipais que porventura contrariem a Constituição Federal; Lei anterior à Constituição que não foi recepcionada; Decretos e atos infralegais (que não sejam autônomos);

\footnotetext{
${ }^{8}$ Art. 103. Podem propor a ação direta de inconstitucionalidade e a ação declaratória de constitucionalidade:

I - o Presidente da República;

II - a Mesa do Senado Federal;

III - a Mesa da Câmara dos Deputados;

IV a Mesa de Assembléia Legislativa ou da Câmara Legislativa do Distrito Federal;

V o Governador de Estado ou do Distrito Federal;

VI - o Procurador-Geral da República;

VII - o Conselho Federal da Ordem dos Advogados do Brasil;

VIII - partido político com representação no Congresso Nacional;

IX - confederação sindical ou entidade de classe de âmbito nacional.
} 
Decisão judicial que não admita recurso ou meio capaz de evitar a lesividade; Ato ou omissão do poder público que não admita outro meio capaz de evitar a lesividade e leis revogadas. (NUNES JÚNIOR, 2019, p. 598).

$O$ ajuizamento de ADPF como instrumento de enfrentamento de violações de direitos: Análise das ações propostas contra legislações educacionais de municípios do Paraná

No Brasil, o complexo cenário político, repleto de disputas de interesses, pode ser evidenciado pela formulação de normativos duvidosos e contraditórios no que se refere ao respeito aos princípios constitucionais. Esta tendência acabou por ampliar a influência política do STF, que atende à crescente demanda por reparação de lacunas e ofensas à lei magna, cada vez mais recorrentes, ascendendo seu protagonismo em decisivos debates sociopolíticos (MARTINS, 2014, p. 248).

No que se refere à temática de gênero e diversidade, o instrumento da ADPF tem sito utilizado cada vez mais frequência. Para ilustrar esta afirmação, é possível mencionar o julgamento da ADPF 132, que objetivava a ampliação dos benefícios previdenciários concedidos aos parceiros homossexuais para outras esferas sociais e unidades da federação (analisada em conjunto com a Ação Direta de Inconstitucionalidade -ADI 4277, que por sua vez buscava a interpretação extensiva do artigo 1723 do Código Civil, reconhecendo os efeitos do instituto do reconhecimento da união estável aos casais homossexuais).

Outro emblemático caso com grande repercussão foi $o$ julgamento da ADPF 54, em 2012, que determinou ser inconstitucional interpretação relativa à tipificação penal da interrupção de gravidez de feto anencéfalo. Este julgamento representou importante conquista no que se refere ao respeito aos direitos reprodutivos (BARBOZA; DEMÉTRIO, 2019). 
Estes exemplos demonstram que a utilização de ações como ADPF tem tido relevantes consequências no ordenamento jurídico no que se refere à proteção de direitos, não obtidos por vias tradicionais, tais quais a esfera legislativa. É neste contexto que se insere o ajuizamento de ADPF para analisar os normativos aprovados vetando a temática de gênero na escola, fato que ocorreu em inúmeros municípios e estados no Brasil.

Neste aspecto, o Estado do Paraná destacou-se negativamente, contando com o ajuizamento de quatro ADPFs para questionar legislações relacionadas à questão de gênero aprovadas pelos municípios analisados neste trabalho. Paranaguá, Cascavel, Foz do Iguaçu e Londrina inseriram em seus ordenamentos dispositivos vedando expressamente a inclusão da temática de gênero e diversidade no âmbito escolar, acompanhado o retrocesso trazido pela retirada da questão de gênero do Plano Nacional de Educação, aprovado em 2014.

Os dispositivos aprovados inseriram-se, em Paranaguá e Cascavel, na própria lei que aprovou os respectivos Planos Municipais de Educação, enquanto que em Londrina e Foz do Iguaçu, a inclusão do dispositivo se deu através de emenda à Lei Orgânica do Município. Em todas as situações, o processo de aprovação foi acompanhado de ruidosas polêmicas envolvendo setores contrários e favoráveis às medidas. A aprovação das disposições, entretanto, foi obtida sem grandes dificuldades.

De acordo com os requerentes quando do ajuizamento das ações, os dispositivos impugnados, ao vetar políticas de ensino relacionadas à questão de gênero contrariam os dispositivos constitucionais de "construir uma sociedade livre, justa e solidária" (art. $\left.3^{\circ}, \mathrm{I}\right)$, ao direito à igualdade (art. $5^{\circ}$, caput); à vedação de censura em atividades culturais (art. 5', IX); ao devido processo legal substantivo (art. 50, LIV); à laicidade do estado (art. 19, I); à competência privativa da União para legislar sobre diretrizes e bases da educação nacional (art. 22, XXIV); ao pluralismo de ideias e de concepções pedagógicas (art. 206, I) e ao 
direito à liberdade de aprender, ensinar, pesquisar e divulgar o pensamento, a arte e o saber (art. 206, II).

As ações buscando enfrentar as legislações dos municípios de Cascavel e de Paranaguá foram ajuizadas na mesma data, em 06 junho de 2017, pela Procuradoria Geral da República (ADPF 460 e 461, respectivamente).

Em Paranaguá, o trecho impugnado estava presente entre as diretrizes do Plano Municipal de Educação9 ${ }^{9}$ que continha a seguinte previsão:

Art. $3^{\circ}$ São diretrizes do PME:

X - Promoção dos princípios do respeito aos direitos humanos, à diversidade e à sustentabilidade socioambiental, sendo vedada entretanto a adoção de políticas de ensino que tendam a aplicar a ideologia de gênero, o termo "gênero" ou "orientação sexual" (PARANAGUÁ, 2015).

O processo contou com a participação de diversas entidades na condição de amicus curiae ${ }^{10}$, tais como Grupo Dignidade - pela Cidadania de Gays, Lésbicas e Transgênero; Associação Nacional de Travestis e Transsexuais (ANTRA), Associação Nacional De Juristas Evangélicos (ANAJURE), entre outros.

Já no mês da propositura, foi deferida liminar para suspender os efeitos do trecho em discussão. Nos fundamentos da decisão, o Ministro relator, Luís Roberto Barroso, entendeu que a escola, "principal espaço de aquisição de conhecimento e de socialização das crianças", ao não enfrentar questões relacionadas ao preconceito e estigma, contribuiria para a reprodução das condutas e continuidade da violação da autoestima e da dignidade de crianças e jovens. O deferimento da

\footnotetext{
${ }^{9}$ Lei 3.468 de 23 de junho de 2015

10 A designação, traduzida como "amigo da corte" é dada a organizações ou pessoas que não figuram como parte no processo, mas possuem interesse jurídico, econômico ou político no resultado processual, e que podem ser admitidas para apresentar suas razões (BARROSO, 2012).
} 
liminar teve relevante repercussão, motivando até mesmo a apresentação de nota de repúdio por parte da Câmara de vereadores do município.

Em Cascavel, a impugnação direcionou-se ao parágrafo único do art. $2^{\circ}$ da Lei 6.496, de 24 de junho de 2015, com redação semelhante ao trecho do município de Paranaguá, reproduzido também na estratégia 8.9, relacionada à meta de elevação de escolaridade. A ação também contou com a participações de diversos atores e organizações, o que sem dúvida enriqueceu grandemente o debate.

Na manifestação apresentada pelo município de Cascavel no curso do processo, indicou-se que a lei combatida teria surgido “[...]como forma de impedir os abusos cometidos por alguns profissionais da educação que fazem uma verdadeira doutrinação nos alunos com relação a orientação sexual[...]" (peça 11, pág. 02), e que a vedação da temática teria o objetivo de preservar a liberdade de crença. As demais ações analisadas ampararam-se em argumentação semelhante, mas foram propostas por diferentes atores.

Em Foz do Iguaçu, a ADPF 526 foi proposta pelo Partido Comunista do Brasil, em 25 de junho de 2018. A norma impugnada, incluída na Lei Orgânica Municipal pela Emenda no 47/2018 de 03 de maio de 2018, incluiu no $\S 5^{\circ}$ do art. 162, a vedação de adoção, divulgação, realização ou organização de políticas de ensino, currículo escolar, disciplina obrigatória, complementar ou facultativa, ou ainda atividades culturais que tendam a aplicar a ideologia de gênero, o termo "gênero" ou "orientação sexual" nas dependências de quaisquer das instituições da rede municipal de ensino.

A justificativa da proposta da emenda, reproduzida na petição inicial apresentada no ajuizamento da ação, indicou que a ideologia de gênero seria "crime" em vários aspectos, pois permitiria que a "administração central" decidiria o que o aluno deve aprender, ignorando o direito de escolha dos pais à metodologia. Indicou que configuraria uma afronta dos administradores com suas "agendas 
panfletárias à educação formativa fornecida pelos pais de acordo com os seus preceitos, opiniões, crenças e tradições, numa clara forma de doutrinação ideológica", e que promover o tema consistiria em que "ignorar o indivíduo em prol da formação de militância e blocos coletivos"(FOZ DO IGUAÇU, 2018).

Por fim, em Londrina, a ação (ADPF $n^{\circ}$ 600) foi proposta pela Confederação Nacional dos Trabalhadores em Educação e pela Associação Nacional de Juristas pelos Direitos Humanos de Lésbicas, Gays, Bissexuais, Travestis, Transexuais, Transgêneros e Intersexuais ANAJUDH LGBTI, em 10 de julho de 2019.

O dispositivo questionado foi aprovado como emenda à Lei Orgânica n. ${ }^{\circ}$ 55, de 14 de setembro de 2018, para a inclusão do artigo 165-A da Lei fundamental do município:

Art. 165-A. Ficam vedadas em todas as dependências das instituições da Rede Municipal de Ensino a adoção, divulgação, realização ou organização de políticas de ensino, currículo escolar, disciplina obrigatória, complementar ou facultativa, ou ainda atividades culturais que tendam a aplicar a ideologia de gênero e/ou o conceito de gênero estipulado pelos Princípios de Yogyakarta (LONDRINA, 2018).

Como é possível verificar, o dispositivo da norma aprovada em Londrina, além da vedação genérica, proíbe a utilização do conceito de gênero previsto pelos Princípios de Yogyakarta aprovados em conferência organizada pela Comissão Internacional de Juristas na Indonésia, em 2006. Em relação a este documento, cabe ressaltar que seu objetivo foi, em síntese, afirmar a obrigação dos Estados na implementação de direitos humanos, sobretudo no que se refere a questões de orientação sexual e identidade de gênero (INDONÉSIA, 2006).

Nas razões apresentadas pelas entidades responsáveis pela propositura, o vício contido no trecho impugnado seria ainda mais 
grave, pois indicaria a proibição da utilização conceito estabelecido em princípios de interpretação do direito internacional.

Verifica-se que todos os municípios se utilizaram do termo "ideologia de gênero" para justificar a declarada censura em relação ao tema de gênero e diversidade, sem a necessidade de qualquer amparo científico ou legal para subsidiar a inclusão da vedação nas normas aqui analisadas. Em verdade, não houve qualquer constrangimento na afronta e descumprimento a diplomas internacionais e domésticos acerca do tema, que há muito estabelecem o dever do Estado na promoção de políticas públicas relacionadas à gênero e diversidade para a obtenção da igualdade e superação da violência sofrida por grupos vulneráveis.

O descumprimento à própria Constituição Federal também restou evidente, e este foi também o entendimento do tribunal: todas as ADPFs foram julgadas procedentes pelo STF, sendo declarada a inconstitucionalidade dos trechos impugnados e tornando sem efeito suas disposições.

O Tribunal entendeu, por unanimidade, que os trechos combatidos possuíam os vícios da inconstitucionalidade formal e material, reconhecendo as razões apresentadas pelos requerentes. Diversos foram os argumentos utilizados, que se amparam não apenas em princípios e dispositivos da Constituição Federal, mas em inúmeros diplomas legais e convenções internacionais sobre o tema. A seguir, destacaremos alguns dos argumentos utilizados na fundamentação das decisões.

No julgamento das ações, ressaltou-se que dispositivos aprovados pelos municípios representariam uma invasão à competência privativa da união, prevista no art. 22, XXIV da Constituição Federal, para legislar sobre diretrizes e bases da educação nacional.

Em relação a este aspecto, foi sublinhado que no exercício desta competência legislativa, a união editou a Lei $n^{0}$ 9.394/96 - Lei de 
Diretrizes e Bases da Educação Nacional-, que estabelece como princípios do ensino II - liberdade de aprender, ensinar, pesquisar e divulgar a cultura, o pensamento, a arte e o saber; III - pluralismo de ideias e de concepções pedagógicas; IV - respeito à liberdade e apreço à tolerância. De acordo com a Ministra Carmen Lúcia na análise da legislação de Foz do Iguaçu, o dispositivo inserido na norma teria estabelecido premissas absolutamente contrárias à tais princípios. Nestes termos, em que pese a competência complementar dos municípios para editar normas educacionais ${ }^{11}$ estas não podem violar as regras gerais estabelecidas pela União.

De acordo com o relator Luiz Fux, no voto da ADPF 460 que analisou a legislação do município de Cascavel, houve clara violação aos valores democráticos e ao pluralismo de ideias. A suposta busca por neutralidade ideológica na qual se amparou a inclusão do dispositivo na lei, assim, é claramente inconstitucional. Para o relator,

a doutrinação ideológica se combate com o pluralismo de ideias e perspectivas - jamais com a censura. Por integrar o conceito de educação, o pluralismo de ideais constitui dever também da família, cabendo-lhe zelar pela liberdade de aprendizado e divulgação do pensamento, da arte e do saber (2020, p. 21).

Compartilhando da interpretação, o ministro Gilmar Mendes, na análise da legislação de Foz do Iguaçu, aduziu que a ausência de debate sobre questões envolvendo sexo e gênero não equivaleria à "neutralidade" sobre o tema. Em verdade, "reflete uma posição política e ideológica bem delimitada, que opta por reforçar os preconceitos e a discriminação existentes na sociedade" (2020, p.13).

Nestes termos, a vedação da temática estabeleceria uma censura que não apenas restringe o contato do aluno a valores morais políticos e ideológicos, mas à liberdade de ensinar, aprender, pesquisar e divulgar o pensamento, a arte e o saber, diretrizes fundamentais da 
educação estabelecida pelo art. 206, II, da Constituição Federal, impossibilitando a problematização de temas da realidade política e social do país na escola, criando entraves à formação do pensamento crítico. Ainda de acordo com ministro, restringir tais liberdades e direitos seriam características típicas de estados totalitários.

Para o ministro Luiz Barroso, relator da ADPF que analisou a legislação do município de Londrina, o veto inserido nas normas viola ainda o princípio da proteção integral da criança, do adolescente e dos jovens, contido no art. 227 da Carta Magna:

em virtude da condição de fragilidade e de vulnerabilidade das crianças, dos adolescentes e dos jovens, a Constituição sujeita-os a um regime especial de proteção, para que possam se estruturar como pessoas e verdadeiramente exercer a sua autonomia. Educar jovens sobre gênero e orientação sexual integra tal regime especial de proteção porque é fundamental para permitir que se desenvolvam plenamente como seres humanos. Por óbvio, tratar de tais temas não implica pretender influenciar os alunos, praticar doutrinação sobre o assunto ou introduzir práticas sexuais. Significa ajudá-los a compreender a sexualidade e protegê-los contra a discriminação e a violência (Voto do relator, ADPF 600, 2020).

Acompanhadas de sólido amparo teórico e jurisprudência, as decisões acima analisadas reiteram o que já vinha defendido pelos atores engajados na luta pela igualdade de gênero: Impedir a inclusão e discussão da temática de gênero e diversidade nas escolas consiste em séria violação de direitos humanos que não pode ser admitida. A construção de uma sociedade democrática só é possível a partir da convivência com a pluralidade e respeitos às diferenças. A total procedência das ações reflete tais conclusões, representando significativo reconhecimento da importância e legitimidade da agenda.

\section{Considerações finais}


Algumas reflexões podem ser realizadas a partir da análise apresentada neste trabalho. Em primeiro lugar, o papel que tem desempenhado o poder legislativo, não no atendimento das demandas da sociedade e proteção de direitos, mas na satisfação de interesses de grupos de influência, tais como conservadores e religiosos. A utilização de estratégias tais como a propagação de informações distorcidas acerca da questão de gênero é um exemplo claro desta afirmação.

As disputas e agendas de interesses alheios ao trabalho que deveria ser realizado pela instância legislativa ficam cada vez mais evidentes na atuação dos parlamentares, fato que paulatinamente tem alçado o STF ao papel de paladino na proteção de direitos, sendo demandado com cada vez mais frequência para sanar gritantes vícios resultantes da atuação parcial do poder legislativo.

Apesar de representar um recurso de extrema importância no impedimento de retrocessos, sobretudo em nosso cenário político atual, depender da atuação do STF para a proteção de direitos é um grande risco. Primeiramente, porque que o controle de constitucionalidade deveria ser uma exceção. Se algo eventualmente não ocorresse conforme os interesses da sociedade, representados pela Constituição Federal, a atuação do STF serviria para sanar o erro.

Assim, seu protagonismo recente é desacertado, e se deve, sobretudo, à omissão e arbitrariedades dos demais atores responsáveis pela manutenção e proteção do estado democrático de direito, fato que coloca o STF na posição de definir quais temas são relevantes socialmente, ficando a seu critério quando serão discutidos e, em última instância, de dizer, a partir de suas decisões, qual é a vontade popular naquela circunstância, diminuindo o peso da participação coletiva nas decisões, pilar de uma sociedade democrática.

\section{Referências}


BARBOZA, Estefânia Maria de Queiroz; DEMETRIO, André. Quando o gênero bate à porta do STF: a busca por um constitucionalismo feminista. Revista Direito GV, v. 15, n. 3, 2019.

BARDIN, L. Análise de conteúdo. São Paulo: Edições 70, 2011, 229p.

BARROSO, Luís Roberto. O controle de constitucionalidade no direito brasileiro. Saraiva Educação SA, 2012.

BRASIL. [Constituição (1988)]. Constituição da República Federativa do Brasil de 1988. Brasília, DF: Presidência da República, [2020]. Disponível

em: http://www.planalto.gov.br/ccivil_03/constituicao/constituicaoco mpilado.htm. Acesso em: 18 ago. 2020.

BRASIL. Lei $n^{0} 11.340$, de 7 de agosto de 2006. Cria mecanismos para coibir a violência doméstica e familiar contra a mulher. Diário Oficial da União, Brasília, DF, 08 de agosto.2006. Seção 1, p. 01

BRASIL. Supremo Tribunal Federal (Plenário). Arguição de descumprimento de preceito fundamental 460 com ajuizada por Procuradoria Geral da República contra o parágrafo único do artigo $2^{\circ}$ da Lei $n^{\circ}$ 6.496/2015 do Município de Cascavel/PR. Relator: Luiz Fux. 29 de junho de 2020. Disponível em: http:/ / portal.stf.jus.br/ processos/detalhe.asp?incidente $=5204904$ Acesso em: 21 ago. 2020.

BRASIL. Supremo Tribunal Federal (Plenário). Arguição de descumprimento de preceito fundamental 461 com ajuizada por Procuradoria Geral da República contra art. $3^{\circ}$, X, da Lei $n{ }^{\circ} 3.468$ de 23 de junho de 2015 do Município de Paranaguá/PR. Relator: Roberto Barroso. 24 de agosto de 2020. Disponível em: http:/ / portal.stf.jus.br/ processos/detalhe.asp?incidente $=5204906$ Acesso em: 27 ago. 2020.

BRASIL. Supremo Tribunal Federal (Plenário). Arguição de descumprimento de preceito fundamental $526 \mathrm{com}$ ajuizada por Partido Comunista do Brasil contra o $\S 5^{\circ}$ do art. 162 da Lei Orgânica do Município de Foz do Iguaçu, acrescido pela Emenda n. 47/2018. Relatora: Min. Carmen Lúcia. 11 de maio de 2020. Disponível em: http:/ / portal.stf.jus.br/ processos/ detalhe.asp?incidente $=5496114$ Acesso em: 21 ago. 2020. 
BRASIL. Supremo Tribunal Federal (Plenário). Arguição de descumprimento de preceito fundamental 600 ajuizada por Confederação Nacional dos Trabalhadores em Educação contra emenda à Lei Orgânica do Município de Londrina/PR n ${ }^{\circ}$ 55, de 14 de Setembro de 2018 que acrescenta artigo 165-A. Relator: Roberto Barroso. 24 de agosto de 2020. Disponível em: http:/ / portal.stf.jus.br/ processos/detalhe.asp?incidente $=5733808$ Acesso em: 27 ago. 2020.

CASCAVEL. Lei $n^{\circ} 6.496$ de 24 de junho de 2015. Aprova o Plano Municipal de Educação do Município de Cascavel/PR para a vigência 2015 - 2025. Cascavel: Câmara Municipal, [2015].Disponível_em:http://www.camaracascavel.pr.gov.br/image s/stories/leis/files/6_496.pdf Acesso em: 24 ago. 2020.

CONVENÇÃO INTERAMERICANA PARA PREVENIR, PUNIR E ERRADICAR A VIOLÊNCIA CONTRA A MULHER, 09/06/1994. Disponível em: <http://www.cidh.org/Basicos/Portugues/m.Belem.do.Para.htm> Acesso em 14 de janeiro de 2020

FOZ DO IGUAÇÚ. Emenda À Lei Orgânica nº 47, de 03 maio de 2018. Acrescenta dispositivo à Lei Orgânica do Município de Foz do Iguaçu, vedando a adoção e/ou divulgação de políticas de ensino que tendam a aplicar a ideologia de gênero. Foz do Iguaçu: Câmara Municipal, [2018]. Disponível em: https://leismunicipais.com.br/a/pr/f/fozdo-iguacu/emenda-a-leiorganica/2018/4/47/emenda-a-leiorganica-n-47-2018-acrescentadispositivo-a-lei-organica-domunicipio-de-foz-do-iguacu-vedando-a-adocao-e-ou-divulgacao-depoliticas-de-ensino-que-tendam-a-aplicar-a-ideologia-de-genero. Acesso em: 24 ago. 2020.

LONDRINA. Emenda À Lei Orgânica No 55, De 14 De Setembro De 2018. Acrescenta artigo 165-A - à Lei Orgânica do Município de Londrina, na parte do Capítulo III, Seção I, que trata da Educação. Londrina: Câmara Municipal, [2015]. Disponível em: https:/ /www.cml.pr.gov.br/leis/2018/web/EL000552018consol.ht ml. Acesso em: 24 ago. 2020. 
MARTINS, Leonardo. Reconhecimento da união estável homoafetiva como direito fundamental pela Justiça Constitucional. University of Brasília Law Journal (Direito. UnB), v. 1, n. 1, p. 721, 2016.

MENDES, Conrado Hübner. Controle de constitucionalidade e democracia. Elsevier Brasil, 2008.

MISKOLCI, Richard; CAMPANA, Maximiliano. "Ideologia de gênero": notas para a genealogia de um pânico moral contemporâneo. Sociedade e Estado, v. 32, n. 3, p. 725-748, 2017.

NUNES JÚNIOR, Flávio Martins Alves. Curso de direito constitucional. 3. ed. São Paulo: Saraiva Educação, 2019.

PARANAGUÁ. Lei $n^{\circ} 3.468$ de 23 de junho de 2015. Aprova o Plano Municipal de Educação do Município de Paranaguá e dá outras providências. Paranaguá: Câmara Municipal, [2015]. Disponível em: https:/ /leismunicipais.com.br/plano-municipal-de-educacaoparanagua-pr. Acesso em: 24 ago. 2020.

PRINCIPIOS DE YOGYAKARTA. Indonésia, 2006. Disponível em: http:// www.clam.org.br/uploads/conteudo/principios_de_yogyak arta.pdf

REIS, Toni; EGGERT, Edla. Ideologia de gênero: uma falácia construída sobre os planos de educação brasileiros. Educação E Sociedade, v. 38, n. 138, p. 9-26, 2017. 